\title{
Detroit's East Side Village Health Worker Partnership: Community-Based Lay Health Advisor Intervention in an Urban Area
}

\author{
Edith A. Parker, DrPH \\ Amy J. Schulz, $\mathrm{PhD}$ \\ Barbara A. Israel, DrPH \\ Rose Hollis, BA
}

\begin{abstract}
In recent years, there have been few reports in the literature of interventions using a lay health advisor approach in an urban area. Consequently, little is known about how implementation of this type of community health worker model, which has been used extensively in rural areas, may differ in an urban area. This article describes the implementation of the East Side Village Health Worker Partnership, a lay health advisor intervention, in Detroit, Michigan, and notes how participatory action research methods and principles for community-based partnership research are being used to guide the intervention. Findings are presented on how the urban context is affecting the design and implementation of this intervention. Implications of the findings for health educators are also presented and include the utility of a participatory action research approach, the importance of considering the context and history of a community in designing a health education intervention, and the importance of recognizing and considering the differences between rural and urban settings when designing a health education intervention.
\end{abstract}

\section{INTRODUCTION}

Health education interventions involving community health workers have been carried out overseas ${ }^{1-4}$ and in the United States ${ }^{5-11}$ to improve health outcomes of "traditionally underserved" populations. Within the United States, a growing number of professionals are working with lay health advisors (LHAs) as a strategy for reaching traditionally

Edith A. Parker is an assistant professor at the University of Michigan, School of Public Health. Amy J. Schulz is a senior social science research associate at the University of Michigan, School of Public Health. Barbara A. Israel is a professor at the University of Michigan, School of Public Health. Rose Hollis is a community health coordinator at the Detroit Health Department, Michigan.

Address reprint requests to Edith A. Parker, DrPH, University of Michigan, School of Public Health, 1420 Washington Heights, Ann Arbor, MI 48109-2029; phone: (313) 763-0087; fax: (313) 763-7379.

The East Side Village Health Worker Partnership was developed in conjunction with the Detroit CommunityAcademic Prevention Research Center, funded through a cooperative agreement with the Centers for Disease Control and Prevention. We are indebted to the members of the East Side Village Health Worker Partnership (Butzel Family Center, Detroit Health Department, Friends of Parkside, Henry Ford Health Systems, Kettering/ Butzel Health Initiative, Mack Alive, Warren/Conner Development Coalition) and the residents of Detroit's east side who helped bring this project to fruition. In addition, we thank Sue Andersen for her invaluable assistance in the preparation of this manuscript. 
underserved populations. ${ }^{12,13}$ While there are similarities across LHA programs, notable differences have emerged among the strategies. Eng and colleagues ${ }^{13}$ suggest conceptualizing differences among these programs on a continuum of formal to informal helping. The formal end of the continuum consists of the paraprofessional/outreach LHA intervention strategy, and the informal end of the continuum consists of what has been called the natural helping LHA strategy. ${ }^{13}$ The natural helping LHA strategy involves identifying individuals within existing social networks who are respected, trusted, and to whom others turn for social support.

The village health workers (VHWs) described in this article are selected based on their identification as natural helpers within the social networks of the intervention population. They are people who are well respected and trusted and are identified by asking, "who do people in this community turn to for help and assistance?"12-15 Natural helper LHAs are not paid employees of any one agency since they are already providing assistance as informal caregivers in their communities. However, programs may provide stipends to offset expenses they incur (e.g., transportation and child care expenses). Natural helper LHAs can fulfill several roles. They can promote positive health behaviors and coping strategies among network members through the provision of interpersonal counseling, referrals, information, and direct assistance. They can also promote ties between community members and service providers by receiving and giving referrals and communicating needs to service organizations. However, natural helper LHAs differ from more formal paraprofessional lay health advisors or community health workers "whose role is to persuade residents to accept services ... [and] to teach and motivate the population to use and comply with existing regimens of care" (p. 29). ${ }^{12}$ In general, natural helper LHAs provide information and mobilize resources to "advocate for improvements in the health care system. Natural Helper LHAs are not expected to serve as a substitute for a professional but are expected to function as an advocacy group" (p. 29). ${ }^{12}$ Natural helper lay health advisors can advocate for their community and work to bring about change that makes services more accessible or appropriate (e.g., changes in hours, decision-making processes). Furthermore, such natural helper lay health advisors can promote an environment conducive to health by facilitating community organizing and policy change activities in the networks and communities of which they are a part.

While different configurations of these community health worker models have been used overseas and in the United States, few interventions using a natural helper lay health advisor model in an urban area in the United States have been reported in the literature in recent years. ${ }^{5,6}$ Consequently, there is little documentation on planning and implementation of this particular model in contemporary urban settings. This article describes and analyzes one such program, the East Side Village Health Worker Partnership, which was implemented in Detroit, Michigan, in 1996, and considers implications for health educators implementing this model in urban areas more broadly.

The East Side Village Health Worker Partnership focuses on improving the health and well-being of women and children living in a defined area in Detroit's east side. A community-based, participatory action research approach is being used to ensure that the lay health advisor model is adapted to the context and setting of this particular urban area. The overall agenda of this intervention research is to identify stressors and protective factors in this urban environment that contribute to poor health outcomes for women and children and to involve VHWs in implementing strategies that either reduce stressors or increase protective factors, such as social support and control, which may buffer the ill effects of these stressors. ${ }^{16}$ 


\section{PROJECT BACKGROUND}

The East Side Village Health Worker Partnership is one of the projects in the overall Detroit Community-Academic Prevention Research Center (PRC). The PRC was funded in October 1995 through a cooperative agreement with the Centers for Disease Control and Prevention, as part of their urban health initiative. The PRC is a partnership between the Detroit Health Department, a managed care organization, the University of Michigan School of Public Health, and several community organizations. The PRC seeks to promote and conduct collaborative, community-based prevention research that strengthens the ability of communities to address and expand the knowledge base of public health regarding the health of women and children. The focus on the health of women and children was initially suggested by the Detroit Health Department due to both high rates of exposure to environmental and structural factors (e.g., lead base paint, poverty) and poor women's and children's health indicators. Guiding the research activities of the PRC is a set of community-based public health research principles ${ }^{17}$ that serve as guidelines to ensure that all research activities benefit the community and actively involve representatives of the partner organizations in all major phases of the research process. The PRC focuses its activities in seven geopolitical subcommunities of Detroit, five in the predominantly African American east side of Detroit and two in southwest Detroit, in which the majority of the Latino population of the city resides.

The defined intervention area for the East Side Village Health Worker Partnership overlaps two geopolitical communities-Kettering/Butzel and St. Jean. Compared to the entire city of Detroit, the two communities that contain the intervention area had lower median household incomes, a greater percentage of families living below the poverty level, higher unemployment rates, and a higher percentage of female-headed households. In terms of their infant mortality rates, one community's rate was higher than the city's average, and the other community's rate was lower. A comparison of selected 1990 social and health statistics for these two communities and the entire city of Detroit are presented in Table 1.

\section{DESCRIPTION OF CONCEPTUAL FRAMEWORK OF THE EAST SIDE VILLAGE HEALTH WORKER PARTNERSHIP}

Poor health outcomes for women and children, especially those living in cities, have been linked with social, structural, and physical factors in the environment such as poverty status, inadequate housing, unemployment, exposure to toxic metals, minority status, powerlessness or lack of control, and the absence or lack of supportive interpersonal relationships. ${ }^{18-21}$ Furthermore, complications during pregnancy appear to be related to stress experienced by pregnant women during pregnancy. ${ }^{22-24}$ Our goal was to design an intervention that took an ecological approach ${ }^{25}$ and considered not only immediate behavioral factors that have been linked to poor health outcomes for urban women and children but also environmental and social factors.

Building on the work of Israel and her colleagues, ${ }^{16} \mathrm{House},{ }^{26}$ and Katz and Kahn, ${ }^{27}$ an initial conceptual framework was developed (see Figure 1), which postulates that stressors in an individual's environment contribute to an increase in perceived stress in the individual. This increase in perceived stress could then result in short-term responses to stress or strains that then may contribute to enduring adverse health outcomes for women and their children. Of importance in this conceptual sequence from the experience of 
Table 1. Social and Health Statistics for Selected Communities in Detroit, 1990

\begin{tabular}{|c|c|c|c|}
\hline & Detroit & Kettering/Butzel & St. Jean \\
\hline Median household income (\$) & 18,740 & 11,992 & 11,917 \\
\hline \multicolumn{4}{|l|}{$\%$ below poverty } \\
\hline All families & 29 & 37 & 42 \\
\hline Female-headed households & 57 & 63 & 68 \\
\hline Unemployment rate (\%) & 20 & 31 & 34 \\
\hline Female-headed households (\%) & 30 & 35 & 37 \\
\hline$\%$ African American & 76 & 94 & 97 \\
\hline$\%$ Hispanic & 3 & 0 & 0 \\
\hline Population & $1,027,974$ & 31,261 & 23,265 \\
\hline Total live births ${ }^{\mathrm{a}}$ & 23,960 & 718 & 572 \\
\hline \multicolumn{4}{|l|}{ Infant mortality rate } \\
\hline 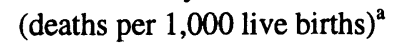 & 20.45 & 30.6 & 14.0 \\
\hline
\end{tabular}

a. Data source for calculations: Michigan Department of Public Health Matched Birth \& Death Tapes, 1990-1994 (Special Project for the Detroit Department of Health).

stressors in the environment to short- and long-term women's and children's health outcomes is the role of conditioning variables. Conditioning variables are individual and situational characteristics that can affect the process through which stressors are experienced as stressful and can affect the relationship of stressors to health outcomes. Conditioning variables can have a positive impact on health by reducing the effect of stress, a negative impact by amplifying its effect, or a neutral role. While most of the research evidence supporting the stress model has focused on the individual as the unit of analysis, Israel and colleagues ${ }^{16}$ suggest the model is appropriate for understanding the effects of stressors at the community level as well. To test this hypothesis, the stress model serves as the conceptual framework for the VHW intervention.

\section{VHW INTERVENTION DESCRIPTION}

The broad goals of the East Side Village Health Worker Partnership are (1) to design, implement, and evaluate a collaborative VHW intervention to address the factors associated with women's and children's health in the targeted area within east-side Detroit; (2) to identify personal, interpersonal, organizational, community, and policy factors associated with poor health outcomes for women and children on Detroit's east side; and (3) to increase VHWs' and community members' knowledge about and participation in strategies to modify risk and protective factors to improve the health of women and children.

The East Side Village Health Worker Partnership builds on a previous VHW project conducted in the northwest area of Detroit through the W. K. Kellogg Foundation-funded Community-Based Public Health Initiative ( $\mathrm{CBPH})$. Through the CBPH project, the Detroit Health Department and other partner organizations established a lay health advisor program and trained 50 village health workers who engaged in projects focusing specifically on increasing the problem-solving capacity of their community as a way to improve health outcomes. ${ }^{8}$ The community health coordinator at the Health Department, who was in charge of implementing the prior CBPH Village Health Worker project, and an assistant community health coordinator, a resident of the east side of Detroit who was 


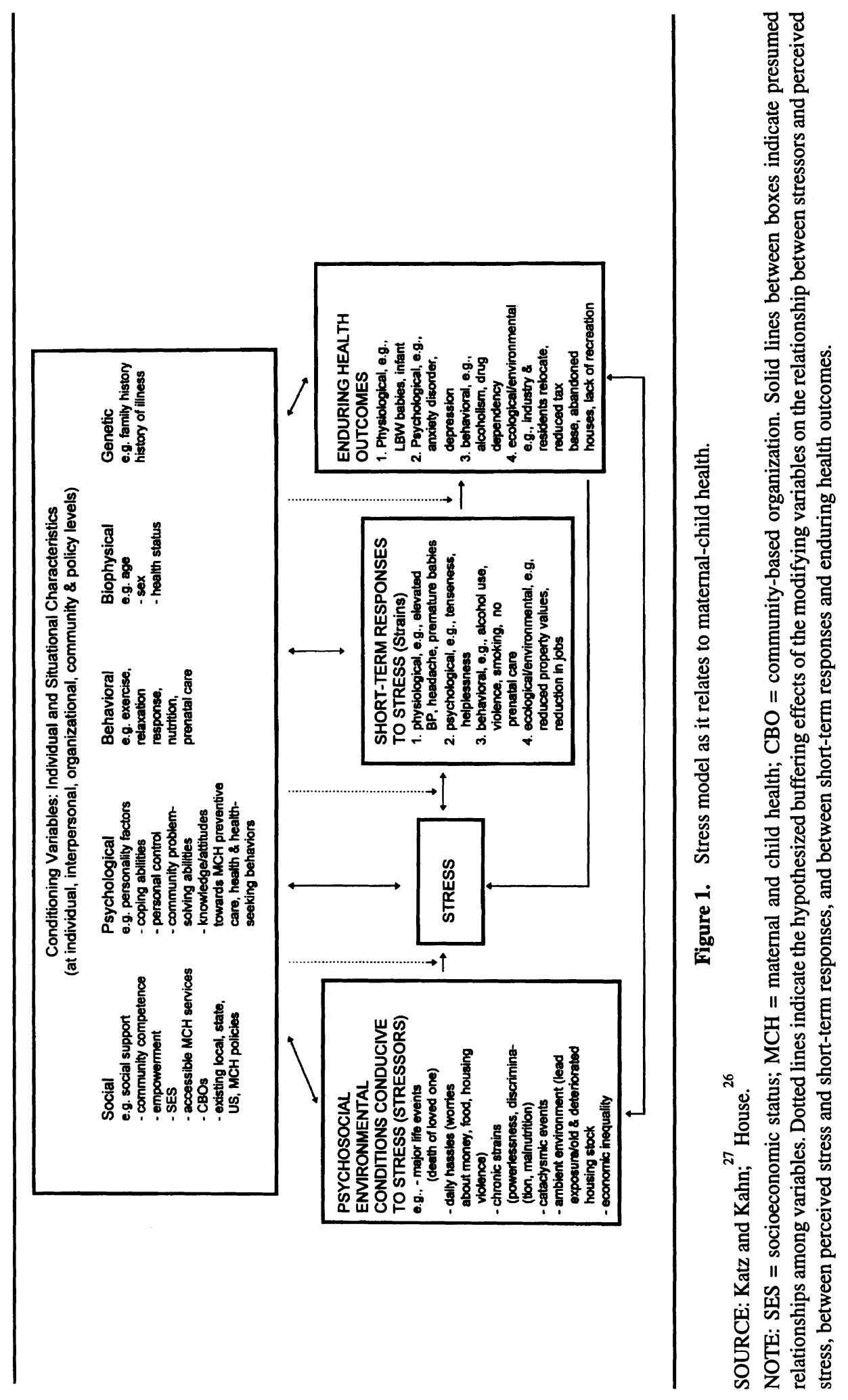


hired through this project, are responsible for implementing the current project. In addition, a steering committee comprising partner organization representatives is responsible for the overall guidance and direction of the project.

\section{METHODS: PARTICIPATORY ACTION RESEARCH AND EVALUATION DESIGN}

The East Side Village Health Worker Partnership uses a participatory action research (PAR) approach in the context of a community-based intervention and thus involves researchers, community members, and practitioners in a joint process aimed at meeting both research and intervention objectives. (For a more complete description of the key characteristics of participatory action research, see Israel et al. ${ }^{16,28}$ )

By using a community-based PAR approach to identify mutually beneficial research and action goals, the East Side Village Health Worker Partnership, at the same time, develops common understandings, shared commitment, and trust among partners. Such a process can help to overcome long-standing mistrust between community members and researchers resulting from past research with little or no immediate benefit and sometimes with detrimental results to community members. ${ }^{29,30}$ With its ongoing reflection, the PAR process allows the insider's view of life to be considered as a crucial element in health education program planning. ${ }^{31}$ Finally, a community-based PAR approach builds on strengths and assets in the community and allows community members to enhance their skills and achieve joint ownership and control of community change efforts. ${ }^{30}$

Within the framework of PAR, the East Side Village Health Worker Partnership involves an extensive evaluation research component that uses a single case study design. ${ }^{32}$ A case study is an empirical inquiry that investigates a contemporary phenomenon within its real-life context. Case studies rely on multiple sources of evidence and are particularly appropriate for addressing "how" and "why" research questions and in situations where the investigator has little control over events. ${ }^{32}$

Although a quasi-experimental research design was considered, the ecological nature of the intervention, with expected activities and outcomes at the individual, interpersonal, organizational, community, and policy levels, led to the decision to use a single case study approach. Green et al. ${ }^{33}$ suggest that ecological, community-based health promotion programs do not readily allow for the assignment of community members into treatment and control groups and that using a control community does not completely solve the problem of comparison since one "cannot assume that a control community will remain static or free of influence by national campaigns or events occurring in the experimental communities" (p. 274). The university team also had ethical concerns about collecting data in a comparison community without being able to ensure an eventual intervention (due to limited funds) in that community, as well as concerns about the ability to adequately "match" two communities on important intervention variables (e.g., social support networks).

It is important to note the disadvantages of using a single case study design. The possibility of threats to the internal validity of the evaluation results, such as maturation or history, are greatly increased with a single case study design. Also, a single case study design limits the ability to prove causation and the generalizability of the evaluation results. However, as noted above, traditional randomized designs or case control designs also face limitations when used at the community level. ${ }^{33}$ While the case study approach does contain disadvantages, it allows for an in-depth examination of both the intervention 
and the context within which it is taking place. This information, if considered with other case studies focusing on the implementation and evaluation of health education interventions in different urban neighborhoods, could provide a foundation for generalizations across these interventions.

Data collection methods for the evaluation include participant observations and field notes of steering committee meetings, VHW training, monthly meetings, and special events; a 700 household face-to-face survey conducted in the first and fourth years of the project; pre- and posttraining assessment of VHWs; focus group interviews with VHWs; in-depth interviews with VHWs, community key informants, health department staff, and other agency and community-based organization staff; documentation records by VHWs and staff; secondary data such as crime statistics and agency referral information; the Geographic Information System (a computerized information system that links health, social, and other data to a geographic unit); and newspaper clippings. The qualitative data are being analyzed in accordance with a focused coding method ${ }^{34-36}$ that will use the constant comparison approach ${ }^{35,36}$ to develop relevant themes. The following description of the intervention of, context for, and implementation of the VHW intervention draws on data gathered from field notes of VHW steering committee meetings, in-depth interviews with key informants and survey interviewers, and field notes from participant observations.

\section{HISTORY AND CONTEXT OF DETROIT}

In any community where life circumstances have the potential to exert a strong negative influence on health status, health educators need to consider the extensive set of skills, strengths, and resources among community members that can be applied to address problems and maintain a positive level of health and well-being. ${ }^{31,37}$ Health education researchers suggest the importance of understanding the history and organization of the community as well as population characteristics when designing interventions. ${ }^{38,39}$ This is particularly true for urban areas that have experienced major changes over the past several decades. In this section, we highlight selected aspects of Detroit's history that influenced our program design and implementation and help in understanding the strengths and problems of today's Detroit.

Population and East/West Distinctions. Detroit is a major metropolitan city with a 1990 population of $1,027,974^{40}$ and is the largest African American majority city in the United States. Like other northern urban cities, Detroit was a destination for many southern African Americans who migrated north for jobs between 1940 and 1960. During those years, Detroit's African American population increased from 150,000 to nearly $500,000 .^{41}$ Many new arrivals resided on the east side, known as the gateway to the city for each successive group of "immigrants." The demarcation between the east side and west side of the city by community residents perhaps is connected to this history of new arrivals' settlement patterns. Perceived differences between the two sides of the city are often referred to in meetings of the VHW steering committee and the PRC board, where residents of the east side are careful to point out to west-side residents that things are "different" on the east side.

These perceived differences have been important to consider as the intervention is implemented. Given that the original VHW model was implemented on the northwest side of Detroit, it has been crucial for university and Health Department staff to recognize 
these perceived differences and not make assumptions that what "worked" on the northwest side is suitable for the east side.

Single-Family Dwellings. One of Detroit's unique features is the number of singlefamily households, with up to three-quarters of the populace living in single-family homes. ${ }^{42,43}$ Of these single-family households, $53 \%$ are owner occupied. The physical presence of single-family households with yards, gardens, and front porches presents a very different environment than other major urban areas in which high-rise apartment buildings dominate. This high proportion of single-family households may affect neighbor networks and neighboring behavior, with some authors suggesting that owners of single-family houses can call on a greater number of neighbors for assistance. ${ }^{44,45}$ Given the emphasis on social support networks in this intervention, the number of single-family dwellings and owner-occupied housing suggested the feasibility of a natural helper lay health advisor approach. The potential differences between home owners and renters in the intervention neighborhoods in terms of their access to social support also needed to be considered.

History of Union and Neighborhood Organizing. Detroit also has a strong history of both union and neighborhood organizing, dating back to at least the 1940s. The United Auto Workers (UAW), the major industrial union within the automobile industry, played a role in workplace desegregation efforts. ${ }^{41}$ Several African American Detroit residents who were union members played active leadership roles in the civil rights movement. As one African American local union leader noted, "Having been union leaders for many years, we thought we had the know-how to change the situation. And after twenty years of existence, we didn't feel we had to wait any longer" (p. 165). ${ }^{41}$ African American labor leaders from Detroit helped organize the Trade Union Leadership Council (TULC) to fight discrimination among labor unions. The TULC also played an important role in the politics of Detroit.

Block clubs have also been an important feature of Detroit's neighborhood life since the 1950s, when hundreds of them were organized in Detroit's neighborhoods through the City Planning Commission's crime prevention and neighborhood preservation programs. These community grassroots organizations, involving African American, white, and other ethnic group members, have focused on improving the quality of life for residents of one or several contiguous blocks. Block club activities have ranged from sponsoring social events for the residents to organizing neighborhood watch programs. Although the city did once try unsuccessfully to stop the program, many of these clubs still remain active today. Given the focus of the VHWs on community organizing, the East Side Village Health Worker Partnership sought to build on these existing block clubs and union and neighborhood organizing expertise and to recruit VHWs from among block club members and community grassroots leaders.

Police-Community Relationships. Like many U.S. urban areas, Detroit has experienced past incidents of extreme tension between the police and African American Detroit citizens. But unlike some other urban areas, Detroit has worked hard to address these tensions. The police department was at the center of the frustration for many African Americans in the 1967 civil unrest. Despite efforts in the early 1960s to integrate the police department, more than $95 \%$ of officers were white in 1967, and they were less than even-handed in their treatment of African Americans. ${ }^{39}$ By the early 1970s, the Detroit police were responsible for the highest number of civilian deaths by police in the country. ${ }^{41}$ Largely due to the efforts of Coleman Young, who was elected mayor in 1973, 
$38 \%$ of the Detroit police force was African American by $1979 .{ }^{41}$ Today, relationships between the police department and the population have improved, and the support and involvement of neighborhood police precincts were a crucial component of the initial VHW project in northwest Detroit. ${ }^{8}$ While east-side residents have voiced frustration with the amount of time it takes police to respond to a call, ${ }^{46}$ they have not expressed the fear or mistrust of the police pervasive in Detroit's past. Given the crucial role of the police in the reduction of neighborhood stressors (e.g., crime, violence) and the relatively positive relationship between Detroit citizens and the police, the East Side Village Health Worker Partnership has actively sought police involvement in the intervention.

Past Racial Tensions. There have been racial tensions in Detroit, with two major events of civil unrest in 1943 and 1967. Conot ${ }^{47}$ attributes the 1943 civil unrest to tensions between African Americans who were frustrated at being "hemmed in geographically, repressed occupationally, restricted to the leavings of the wartime economic feast" (p. 386) and whites who were unhappy with growing civil rights African Americans had gained. In June 1943, these tensions boiled over into fighting that lasted 2 days and resulted in the deaths of 9 whites and 25 African Americans. In 1967, a raid of an illegal after-hours club by the Detroit vice squad set off 4 days of civil unrest in which 43 people died, 347 were seriously injured, 1,300 buildings were destroyed, and 7,000 people were arrested. ${ }^{41}$ While the 1967 event involved little or no direct fighting between white and African American citizens, at its root were inequalities between African Americans and whites in job advancement, employment, housing, education, wages, and income. ${ }^{41}$

Out-Migration. Detroit, like many other urban areas, faces the challenges of unemployment and out-migration of population and businesses to the suburban areas. Among the 77 cities in the United States with populations above 200,000 in 1989, Detroit ranked first in the percentage of the population below the poverty level $(32.4 \%)$ and in unemployment (13.1\%). The rate of migration of both people and industry from the inner city to the suburbs is higher in Detroit than in other cities. ${ }^{48}$ Although the out-migration of white families increased after the 1967 civil unrest, ${ }^{41}$ the decline in the city's white population is part of a 50-year trend and began after World War II, when residents left the city for new residential districts on the urban fringe. .11,47 $^{-}$

These migration patterns have contributed to increasing racial/ethnic segregation in the city of Detroit. ${ }^{49}$ In $1970,46 \%$ of youth under age 18 reported that they were white, and 54\% reported that they were African American; in 1990, those rates were $15 \%$ and $82 \%$, respectively. Nationally, increasing racial/ethnic and economic segregation of urban populations has been linked with decreasing access to social and structural supports within communities of color, such as jobs, stores, and other institutions that have relocated to suburban areas. ${ }^{50,51}$ Indeed, Fainstein et al. ${ }^{52}$ in a study of trends in the Detroit budget between 1966 and 1979, note that industrial and commercial disinvestment severely eroded the Detroit tax base: from 1966-1979, the percentage of Detroit's budget devoted to various social consumption services (e.g., mass transportation, health, sanitation) remained stationary or declined. Neithercut ${ }^{48}$ suggests that due to the reduced city tax base, Detroit youth are growing up in an environment filled with "abandoned and derelict houses, failed houses, failed businesses, unsafe playgrounds and parks, overgrown and debris-strewn vacant lots, and neighbors who are, in many cases, unknown or feared" (p. 15). Recognizing the stressors associated with the out-migration of population and businesses and consequent increased racial/ethnic and economic segregation, the East Side Village 
Health Worker Partnership is taking an ecological approach to understanding and improving women's and children's health. ${ }^{25}$

In summary, both the history and the current statistics of Detroit indicate an urban area with the presence of both life circumstances that have the potential to exert a strong, negative influence on health status and the existence of skills, strengths, and resources among community members to address problems and maintain a positive level of health and well-being. ${ }^{31,37}$ High rates of unemployment, out-migration, and school dropout suggest stressors that can have a negative effect on health. A history of strong local leadership, active block clubs, and effective community political action suggest the presence of "conditioning" variables that can mediate the effects of those sources of stress on health status.

\section{ESTABLISHING THE STEERING COMMITTEE}

The input and influence of the steering committee have been crucial to the development and implementation of the East Side Village Health Worker Partnership. The steering committee has provided advice and guidance for issues as diverse as the delineation of the stress model, selection of the intervention site, procedures for the presurvey block listing, and how best to identify potential VHWs.

For natural helper LHA programs in rural as well as urban areas, one challenge to using a participatory action research approach is to ensure sufficient and diverse representation of community members on a steering committee. While rural areas tend to have concentrated services in main towns and regional service centers ${ }^{53,54}$ and a smaller number of community-based organizations, the urban intervention area described here includes multiple agencies and community groups. While the geographic areas of these agencies and community groups overlap, the populations with whom they work may differ (e.g., one may focus on services for the elderly, while another provides maternal health services). The challenge for the steering committee was to ensure the representation of as many agencies and community groups as possible without expanding to an ineffective number.

Consequently, membership of the East Side Village Health Worker Partnership steering committee has been an evolving process. The steering committee includes representatives of seven community-based organizations/agencies, a managed care system, the Detroit Health Department, and the University of Michigan School of Public Health. When the steering committee began meeting in January 1996, members consisted of representatives from member organizations of the overall PRC board who operate on the east side. These members had been identified as active organizations representing diverse community constituencies by university personnel with extensive work experience on the east side. These groups were initially approached during the grant-writing phase to become part of the PRC and the VHW intervention. An additional community-based organization (CBO) was asked to participate in the VHW project after the grant had been written but before the steering committee began meeting.

Six months into the project, after suggestions by steering committee members that membership needed to be expanded, the steering committee devoted a meeting to the membership issue. Recognizing that there were multiple ways in which other groups could be involved in the intervention, steering committee representatives identified potential agencies and community groups according to three categories: (1) agencies and/or CBOs that would provide possible resources to the VHWs and thus needed to be 
informed of the project by the staff, (2) those agencies and/or CBOs that could help in identifying potential VHWs, and (3) agencies and/or CBOs that should be asked to become members of the steering committee. Based on the list generated, three new organizations were invited to join the steering committee.

Soon after formation, the steering committee was presented with four priority and concurrent tasks: selection of the intervention site, development of the stress process model, assistance in developing items for the survey, and guidance in establishing survey administration procedures. After these tasks were completed, the steering committee focused on the fifth priority task: the identification, selection, and training of VHWs.

\section{SELECTION OF THE INTERVENTION SITE}

One of the first tasks of the steering committee was to select a smaller intervention area within the five east-side Detroit communities (1990 population of 82,182 ). A limited number of VHWs would be trained and active throughout the project, and the partners felt that the effectiveness of the VHW intervention strategy would be facilitated if activities were concentrated in a smaller area. The committee developed a set of criteria to guide the process of selecting a smaller area within which to focus the VHW intervention. These criteria consider data about health and social problems, as well as strengths and assets within the community, such as social networks and churches.

A crucial aspect of assessing the first of the criteria for site selection (i.e., strengths and resources within the community) was the consideration of how a "carved out" geographical intervention site would correspond to the internal organization of the area, as conceptualized by the residents. Steuart ${ }^{31}$ suggests the importance in health education program planning of considering units of identity (units with which individuals feel themselves to be associated) and units of solution (defined as those units appropriate or essential for the solution of particular problems). Neighborhoods may be units of identity if the residents feel a sense of connection and belonging with each other, share needs and aspirations, and experience similar conditions. Units of identity are potential units of solution if the members of that unit of identity work together in collective problem solving. Given the assumption that the VHWs will work within their units of identity, it was crucial to determine what those units were and how often, if at all, they had previously worked together as units of solution.

Determining units of identity requires ascertaining the extent to which community residents perceive a sense of community, ${ }^{16,31,55}$ as well as disentangling geographic neighborhoods from social networks. ${ }^{56}$ Rural natural helper LHA programs often use the neighborhood as the unit of identity for the selection of LHAs. This quote from a resident in a rural town suggests that neighbors in a rural area know their neighbors who need help:

Everybody just about knows everybody in Centertown and Northtown and that makes the difference and those people [lay health advisors] know about everybody. A lot of the people work in Centertown and they come in contact with a lot of the problems in Centertown. So I think they can relate when they come to the meetings, relate to each other what is going on and they can work on it. I think that makes a difference. (p. 88) ${ }^{54}$

Urban neighborhoods with a higher population density and less residential stability may have multiple social networks with little overlap and a less consistent match between 
geographic areas and social networks. This would increase the risk that some neighborhood members will slip through the social safety net.

To aid in determining the complexity of these urban networks and the potential units of identity within this area, we sought input from the steering committee and, in addition, conducted key informant interviews (four individual interviews and a focus group interview with five individuals) with community residents. Questions from the literature on community diagnosis ${ }^{57,58}$ and neighborhood assessment ${ }^{55}$ were included (e.g., respondents' conceptualizations and perceived boundaries of their community, functions of their community, strengths and problems in their community, helping patterns, and history of communal activities, etc.).

The results of these key informant interviews suggested that residents thought of their neighborhoods as a defined spatial area that sometimes had a specific name. For example, one community member described a 38-block area called Hill community (not the real name of the community), explaining that this larger neighborhood was started by building up individual block clubs and that residents of this 38-block area referred to themselves as "Hillites." Another informant referred to living in the "lower east side," described the boundaries of her neighborhood, and then noted that her sense of identity was with the local neighborhood association, composed of several block clubs. Most informants were active in their block clubs and described residents who were older and who owned their homes as more actively involved in their block clubs.

Most informants described strong relationships at the neighborhood level and spoke of "knowing each other," "seeing them [neighbors] frequently." They described their neighborhoods in the following ways: "[It is] a busy street but I know who people are"; "people who've been there are like a community watch, they have a bond that's already there"; "[it is] a neighborhood that's building trust ... we look to each other, know each other, work on problems together, have some coffee, cry on each others shoulders, trust each other, are sincere." Neighborhood concerns that they identified included drug dealers, lack of parenting skills among mothers, lack of supervised activities for children and youth, and violence. Other assets identified included active block clubs and other community organizations, agency services, churches, and active individuals.

Several Geographical Information System maps were produced to aid in the process of synthesizing available information into the site selection process. These maps included information such as total population, the number of female-headed households, median household income, and the number of newborns to 4-year-olds, as well as the information supplied by the key informants and steering committee members (e.g., locations of community-based organizations and schools, health clinics) and census tract, health area, and ZIP code boundaries. After deliberating over the maps and the selection criteria, the committee eventually selected an area of population of approximately 20,000 .

\section{DELINEATING THE STRESS MODEL FOR THE LOCAL AREA}

The steering committee was instrumental in identifying stressors and conditioning variables present in the east side that have the potential to affect the health of women and children. University partners facilitated a guided exercise with the steering committee in which members were asked to identify sources of stress for women who care for children on the east side, how people feel and respond to these sources of stress, what occurs if these stressors continue over a long time period, and what are the factors that can keep these stressors from having a negative effect on people's lives. The steering committee's 
discussion was guided by the conceptual model of the stress process presented earlier (Figure 1), but it identified the specific items relevant to women and children living on the east side.

The steering committee generated a list of 49 different stressors and 25 conditioning variables (see Table 2). Many of these stressors are not unique to women raising children (e.g., worries about money), nor are they unique to urban residents (e.g., problems with health care or access to health care). However, their particular manifestations may differ between rural and urban communities, as well as between and within urban communities. For example, one of the stressors identified by the steering committee was that of "knowing that east-side neighborhoods have more environmental problems than affluent neighborhoods." It has been well documented that urban and rural communities with a high proportion of low-income residents and residents of color are more likely to experience exposure to toxic dumping or other environmental hazards. ${ }^{59,60}$ However, the particular forms of risk exposure may exhibit urban/rural differences and may vary in different urban communities. For example, southwest Detroit has a concentration of industries situated in the midst of densely populated residential communities located on the shores of the Detroit River, where particulate matter is released into the air constantly and effluent is dumped on a regular basis into the Detroit River. ${ }^{61}$ On Detroit's east side, the exodus of residents over the past decades has led to an increase in abandoned houses. Those houses left standing have become sources of crime and fire. ${ }^{48}$ Thus, the category of environmental contaminants may contain many different manifestations of increased risk exposure for both rural and urban communities of color.

Identified stressors associated with food and housing also have uniquely urban attributes. Inner-city residents often pay more than suburban residents for food and items such as housing. As Fainstein and colleagues ${ }^{52}$ note,

\begin{abstract}
Higher rents, escalating insurance rates, loss due to theft, inadequate city services, and local "monopolies" led neighborhood merchants and national chain stores operating in the urban core (of Detroit) to charge higher prices for lower quality goods. Inner-city residents were the least mobile of the metropolitan population and least able to take advantage of shopping alternatives. So the highest prices were paid by those least able to afford them. (p. 95)
\end{abstract}

The identified stressor of loss of loved ones due to violence or sickness also may occur differently in urban areas. A recent study comparing mortality among African American and white adults in low-income rural and urban communities in the United States found that African American adults living in Detroit had among the highest risk of death at all ages when compared to the other communities included in the study. ${ }^{62}$ The high mortality rates among young adults in Detroit reflect the multiple stressors experienced by African Americans living in this particular urban community and suggest that these stressors differ somewhat from those experienced by African Americans living in other urban and rural communities. Furthermore, as the steering committee suggests, these high mortality rates may also contribute to the stress experienced by those who survive the loss of their loved ones.

Included among the conditioning variables (or "what keeps the stressors from being so bad") listed by the steering committee were spirituality and church or mosque membership. Furthermore, steering committee members noted that having family and friends to whom they could turn for support helped to mediate the effects of stressors. Finally, members of the steering committee indicated that the belief that one could work to 


\section{Table 2. Stressors for Women and Child Care Givers Identified by the Steering Committee}

\section{Housing}

Lack of housing

Long wait for subsidized housing

High rent

Poor quality housing

Unresponsive landlords

Rodent and bug problems

Neighborhood/environmental contaminants

Poor environment (abandoned lots and cars, weeds, tires, vacant home, safety problems, illegal dumping, toxic exposure)

Perceptions and reality that neighborhood has more environmental problems than affluent neighborhoods

Worries about money

Wages low for raising kids

Doubts if can afford to raise kids

Cannot afford to pay bills

Having to go on public assistance

Lack of financial support

\section{Transportation}

No school bus or personal transportation

Cannot afford cab or public transportation

In general, lack of transportation

Family/children responsibilities and relationships

Fear for self and my kids' safety

Dealing with children when parent has substance abuse problem (e.g., grandparent, aunt)

Abusive relationship with spouse or significant other (affects couple and kids)

Parents, while facing other stressors (financial, housing, etc.), having to prove themselves as worthy parents when kids removed from home by state

Parents using kids as weapon against each other

Lack emotional support

Lack support from others

Don't feel I have time for myself

Holding on to relationships even if not positive

Lack of stable sexual relationships-keep trying to find such relationships, problems for kids as women spend all their energy finding a man for support

Uncertain bond with child (adoptive/foster parents)

Stressors specific to mothers

Everyone tells mother how to raise kids

For mother with multiple kids, difficult to give attention to all kids as well as táke care of herself, especially when she is pregnant

Father not providing support for kids whether in house or not

Stressors specific to fathers

The way system deals with fathers with regard to child support (e.g., different ways to provide support that mothers and courts do not recognize)

Fathers feeling like they should be with kids but cannot be

Diet/nutrition issues

No food in house (financial)

No time or energy to prepare food

Know you are eating wrong but cannot get away from fast food and nonnutritious foods

Affordability of food-trying to find what is more affordable to "stretch it"

Trying to find knowledge, time, and money to eat well 
Table 2. Continued

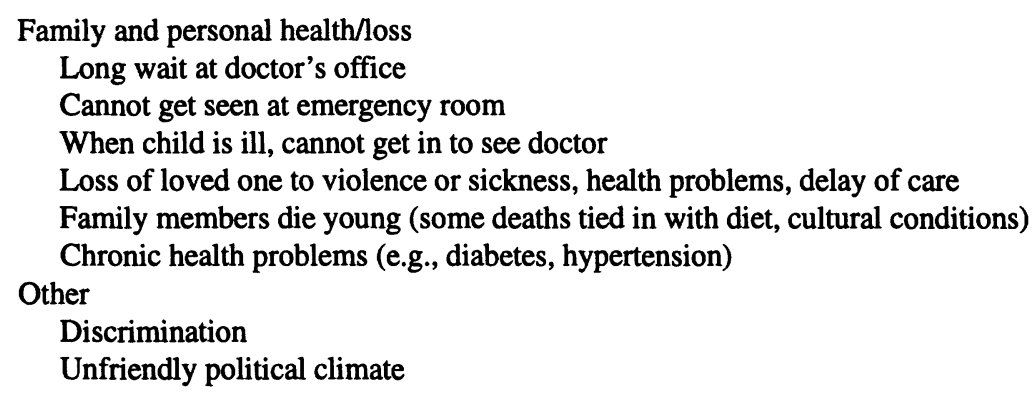

NOTE: Some very similarly identified stressors have been combined.

create change or could do something to make a difference was an important factor in the stress process.

Drawing from the stressors and conditioning variables identified by the steering committee and a review of the literature specific to factors associated with women's and children's health, a 350-item survey questionnaire was developed. The steering committee assisted in determining to whom and how the face-to-face random sample survey would be administered. (For a more detailed description of the survey construction and administration and the steering committee's role in that process, see Schulz et al. ${ }^{63}$ )

\section{IDENTIFICATION AND SELECTION OF VHWS}

Based on experience and the literature on the lay health advisor model, ${ }^{7}$ the staff and steering committee expected attrition in LHAs over time. They decided to recruit and train 50 community members as VHWs, with the intent of retaining 30 active VHWs. The community health coordinator and assistant community health coordinator visited east-side agencies identified as resource and referral agencies for the VHWs to inform them of the project and to ask for names of persons they considered to be natural helpers in the communities they served. In similar programs in rural areas, the identification of natural helpers often follows a reputational method ${ }^{14,53}$ in which those persons whose names are mentioned most frequently are invited, based on their reputation, to become involved in the program as a lay health advisor. To assist agencies and groups in identifying potential VHWs in their communities, a list titled "Things to Look for in Selecting VHWs" was distributed by the staff. This list noted that a VHW must be someone who others already turn to for advice about women's and children's health issues, is caring and has an interest in helping others, is active in and committed to his or her community, is trustworthy and respects confidentiality, is a good listener, and whose name is mentioned when community people are asked, "Who do people in this community or neighborhood go to when they need help?"

Our experience using the reputational method to recruit VHWs on the east side of Detroit differed somewhat from descriptions of this process in rural communities. The groups and agencies contacted had no difficulty in providing names, but few of the names provided appeared on multiple lists. This may be an artifact of the process that, due to time constraints, focused more on contacting service agencies and community-based organizations and less on talking with community residents who were active in block 
clubs and other activities. It is possible that if the process had extended beyond the level of organizational representatives, the same names of lay helpers would have emerged on multiple lists. The community health coordinator has also suggested, based on her many years of community organizing in Detroit, that the reputational process worked differently due to the urban environments' multiple social networks that do not necessarily have overlapping membership. Thus, despite the close geographic proximity, organizations may interact with different subgroups of the population that have little overlap and may not have shared knowledge of the same natural helpers working in the common area they serve.

Whatever the reason, few names appeared on multiple lists at the end of the process of gathering names. As a result, the reputational method was modified so that individuals whose names were mentioned just once were invited to participate in the VHW training. In all, 31 persons attended at least one session of the VHW training, and 23 completed the training. The experience to date suggests that those who completed the VHW training are indeed active in community organizations and appear to be actively engaged in their social networks.

\section{DESCRIPTION OF TRAINING}

The training format for the East Side Village Health Worker Partnership was based on previous trainings conducted for the prior CBPH VHW project in northwest Detroit. Modifications were based on input from the steering committee and addressed the particular focus of this intervention on women's and children's health. The training consisted of nine evening and weekend sessions over a week-and-a-half time period in November 1996 and included a general introduction to the East Side Village Health Worker Partnership and the concept of a VHW, use of assets mapping in neighborhood program planning, ${ }^{64}$ use of photovoice ${ }^{65}$ in needs assessment/policy development at the neighborhood level, community organizing, introduction to agencies and their resources working on the east side, role of the community policing programs in the intervention area, women's and children's health issues, and lead poisoning. A formal graduation ceremony was held at the end of the training, and each graduate received a certificate and a stipend of $\$ 100$.

Pre- and posttraining assessment questionnaires with both open- and closed-ended items were administered to measure participants' knowledge change and assessment of the sessions. The posttraining assessment was repeated 6 months after the completion of the training. A second training series was held in the summer of 1997 to ensure that there would be 30 VHWs active in the intervention area. In addition, ongoing training and monthly meetings have been held to support the work of the VHWs, provide information, and offer opportunities for VHWs to share experiences and assist each other.

\section{DISCUSSION AND IMPLICATIONS FOR HEALTH EDUCATORS}

The East Side Village Health Worker Partnership is still in the early stages of its intervention implementation. Process evaluation documentation to date suggests certain challenges and implications for health educators designing lay health advisor programs in urban areas. These challenges and implications include recognizing the contrasts between implementing lay health advisor interventions in urban as compared to rural 
settings and recognizing the value of a community-based participatory action research approach in ensuring partnership in the program planning and implementation stages and consideration of the context of the setting in which the program will be implemented.

\section{Contrasts Between Urban and Rural Settings}

Several challenges of establishing a lay health advisor intervention in an urban environment are related to the multiple organizations that may exist in any potential intervention area. The first is the identification of organizations that are most appropriate to be involved in the project. Ensuring inclusion of agencies and community groups representing different community constituencies may be more complex in an urban environment and may require constant observation of who has been excluded from the process. The strategy used here-to enter the community through community agencies, community-based organizations, and block clubs-risks excluding persons who may not have strong ties to any of these organizations. For example, one of our key informants described the difficulty of becoming active in a block club for those who were not long-time neighborhood residents. Those who are not part of established block clubs need to be reached through other arenas and avenues and may have different interests and priorities.

A second challenge is the identification of VHWs. While there are numerous reports of the effectiveness of the reputational method working in rural areas, ${ }^{12,14,53}$ in our case, names of potential VHWs were rarely repeated by more than one organization. This suggests that urban communities may encompass more complex social networks with less overlap than those found in rural communities. Thus, it may be more appropriate in urban areas to ensure that individuals are selected from each of many different networks rather than only identifying individuals who are linked across multiple networks.

While rural areas may often have overlapping interventions, the sheer density of population and organizations in urban areas increases the potential for multiple interventions and programs targeting the same areas. This has important implications for both the implementation and evaluation of a health education intervention. For example, near to our intervention area is an LHA intervention employing a paraprofessional/outreach model in which community members are hired by an agency for an hourly wage to conduct specific tasks related to the prevention of drug abuse. The differences and similarities in the two interventions have caused confusion and some disagreement among residents of the east side, which may influence the success of both programs. A related challenge for the East Side Village Health Worker Partnership will be to document this and other health and social programs underway in the intervention area to acknowledge the potential effects these interventions may have on the outcomes of the East Side Village Health Worker Partnership.

Another difficulty is identifying and building on the appropriate units of identity within the intervention area. ${ }^{31}$ The East Side Village Health Worker Partnership recognized that the social networks of residents would likely extend beyond the defined boundaries of the intervention area. As work with neighborhood residents has proceeded, these multiple layers of "community" have become even more apparent. For example, the apparent "east side-west side dichotomy" may be more complex as a number of "cross-over" networks from east to west have been discovered (e.g., west-side residents who attend church and have strong networks on the east side, and vice versa). Given the role of the African American church, this suggests that our focus on a defined geographic 
area may exclude some important mediating structures ${ }^{66,67}$ that are important sources of support for the target population. However, in our key informant interviews, respondents described strong relationships at the neighborhood level, suggesting that the neighborhood is also a viable mediating structure. These results reinforce the importance of conducting a community diagnosis to obtain a better understanding of the units of identity and a sense of community that exist within urban neighborhoods..$^{57,58}$

\section{Value of Participatory Action Research Approach}

The use of a community-based PAR approach helped to tailor the intervention to the needs, values, and context of the local community and fostered ownership and control of the process by the participants themselves. This sense of ownership and control increases the likelihood that the intervention will be sustained beyond the initial project period. Through the steering committee partnership, a conceptual model of the stress process was developed; the intervention focus and methods were jointly identified; a questionnaire and the procedures to administer it were developed; 23 VHWs were identified, recruited, and trained; and the task of jointly identifying all anticipated outcomes of this project is being conducted. While there are a number of challenges in using a PAR approach (see, e.g., Israel et al. ${ }^{30,68}$ ), health educators working in complex urban systems are encouraged to consider applying PAR principles in their work. ${ }^{69}$

\section{Consideration of Community Context}

Considering the context of Detroit has been critical to the implementation of the East Side Village Health Worker Partnership. Problems described in this article, such as out-migration of businesses and a deteriorating tax base, are similar to those in other urban settings. Issues that have been identified in this article, such as working with multiple organizations with overlapping geographic reference areas and the complexity of identifying units of identity in a large urban setting, will be similar in other urban areas of the United States where individuals are members of multiple and overlapping social groups. ${ }^{56}$

However, as the description of the history and context of Detroit suggests, there are also many dynamics specific to Detroit's particular social and political history that shape the pattern of response to these global trends. For example, the history of a strong labor union movement, block-level community organizing, and community relations with the police department combine to create the specific political and social context on which the VHW intervention can build.

The history of a community offers essential information to health educators, allowing them to tailor interventions to fit community characteristics and dynamics-characteristics that may change from neighborhood to neighborhood. Partnerships that involve community members who understand that context and history are invaluable in guiding the development of interventions in urban neighborhoods.

\section{CONCLUSION}

This article describes and analyzes a lay health advisor intervention, with a particular focus on the urban context and setting in which the intervention takes place. The results 
to date of this case study suggest the value of using a participatory action research approach and employing community-based research principles in the planning, implementation, and evaluation of this intervention.

The results to date also suggest that while there are similarities between Detroit and rural areas in which lay health advisor interventions have been implemented, as well as similarities between Detroit and other urban areas, there are also unique features of Detroit that are relevant to the VHW intervention. These findings strongly suggest that an "urban" situation is much more than a variable to be "controlled for" in health education research and evaluation, and the impact of living in an "urban situation" should be more fully considered as an independent variable when studying the health status of urban dwellers. Health education practitioners, researchers, and teachers are urged to continue to contribute to the knowledge and practice base of health in urban areas. Given the growing proportion of people in the world living in urban areas, further knowledge of the effects of urban life on health is of particular importance.

\section{References}

1. Werner D, Bower B: Helping Health Workers Learn. Palo Alto, CA, Hesperian Foundation, 1987.

2. Brieger WR, Ramakrishna J, Adenyi JD, Sridhar MKC, Kale OO: Guineaworm control case study: Planning a multi-strategy approach. Soc Sci Med 32:1319-1326, 1991.

3. Nayak H: Exploring the Use of Community Health Workers in Developing Countries. Unpublished manuscript, Georgetown University, 1991.

4. Chaulagai CN: Urban community health volunteers. World Health Forum 14:16-19, 1993.

5. United States Department of Health and Human Services: Community Health Advisors: Models, Research and Practice, Selected Annotations-United States, Volume I. Atlanta, GA, U.S. Department of Health and Human Services, Public Health Service, Centers for Disease Control and Prevention, National Center for Chronic Disease Prevention and Health Promotion, Division of Chronic Disease Control and Community Intervention, September 1994.

6. United States Department of Health and Human Services: Community Health Advisors: Programs in the United States, Health Promotion and Disease Prevention, Volume II. Atlanta, GA, U.S. Department of Health and Human Services, Public Health Service, Centers for Disease Control and Prevention, National Center for Chronic Disease Prevention and Health Promotion, Division of Chronic Disease Control and Community Intervention, September 1994.

7. Eng E, Smith J: Natural helping functions of lay health advisors in breast cancer education. Breast Cancer Res Treat 35:23-29, 1995.

8. Schulz AJ, Israel BA, Becker AB, Hollis RM: It's a twenty-four hour thing . . . a living for each other concept: Identity, networks, and community in an urban village health worker project. Health Educ Behav, 24:465-480, 1997.

9. Stillman FA, Bone L, Rand C, Levine DM, Becker DM: Heart, body, and soul: A church-based smoking-cessation program for urban African-Americans. Preventive Med 22:335-349, 1993.

10. Eng E, Parker E: Measuring community competence in the Mississippi delta: The interface between program evaluation and empowerment. Health Educ Q 21:199-220, 1994.

11. Meister JS, Warrick LH, DeZapien JG, Wood AH: Using lay health workers: Case study of a community-based prenatal intervention. J Comm Health 17:37-51, 1992.

12. Eng E, Young R: Lay health advisors as community change agents. Fam Comm Health 15:24-40, 1992.

13. Eng E, Parker E, Harlan C: Lay health advisor intervention strategies: Acontinuum from natural helping to paraprofessional helping. Health Educ Behav 24:413-417, 1997. 
14. Service C, Salber E, Jackson J: Identification and recruitment of facilitators, in Service C, Salber EJ (eds.): Community Health Education: The Lay Health Advisor Approach. Durham, NC, Duke University Health Care System, 1979.

15. Israel BA: Community-based social network interventions: Meeting the needs of the elderly. Dan Med Bull 6:36-44, 1988.

16. Israel BA, Checkoway B, Schulz AJ, Zimmerman MA: Health education and community empowerment: Conceptualizing and measuring perceptions of individual, organizational and community control. Health Educ $Q 21: 149-170,1994$.

17. Schulz AJ, Israel BA, Selig SM, Bayer IS, Griffin CB: Development and implementation of principles for community-based research in public health. J Comm Practice, in press.

18. Geronimus A: The effects of race, residence and prenatal care on the relationship of maternal age to neonatal mortality. Am J Public Health 76:1416-1421, 1986.

19. Geronimus A: On teenage childbearing and neonatal mortality in the United States. Population Dev Rev 13:245-279, 1987.

20. LaViest TA: The political empowerment and health status of African-Americans: Mapping a new territory. Am J Sociol 97:1080-1095, 1992.

21. Healthy People 2000: National Health Promotion and Disease Prevention Objectives. U.S. Department of Health \& Human Services, Public Health Service. Boston, Jones \& Bartlett, 1992.

22. Reeb KG, Graham AV, Zyzanski SJ, Kitson GC: Predicting low birthweight and complicated labor in urban black women: A biopsychosocial perspective. Soc Sci Med 25:1321-1327, 1987.

23. Norbeck JS, Tilden V, Peterson L: Life stress, social support and emotional disequilibrium in complications of pregnancy: A prospective, multivariate study. J Health Soc Behav 24:30-46, 1983.

24. James SA: Racial and ethnic differences in infant mortality and low birth weight: A psychosocial critique. Ann Epidemiol 3:130-136, 1993.

25. Stokols D: Translating social ecology theory into guidelines for community health promotion. Am J Health Promotion 10:282-298, 1996.

26. House JS: Work Stress and Social Support. Reading, MA, Addison-Wesley, 1981.

27. Katz D, Kahn R: The Social Psychology of Organizations. New York, John Wiley, 1978.

28. Israel BA, Schurman SJ, House JS: Action research on occupational stress: Involving workers as researchers. Int J Health Serv 19:135-155, 1989.

29. Jones JH: Bad Blood: The Tuskegee Syphilis Experiment. New York, Free Press, 1993.

30. Israel BA, Schulz AJ, Parker EA, Becker AB: Community-based research: A partnership approach to improve public health. Annu Rev Public Health, under review.

31. Steuart GW: Social and behavioral change strategies, in Phillips HT, Gaylord SA (eds.): Aging and Public Health. New York, Springer, 1985.

32. Yin RK: Case Study Research: Design and Methods. Beverly Hills, CA, Sage, 1984.

33. Green LW, Richard L, Potvin L: Ecological foundations of health promotion. Am J Health Promotion 10:270-281, 1996.

34. Patton MQ: Qualitative Evaluation Methods. Beverly Hills, CA, Sage, 1990.

35. Glaser B, Strauss A: The Discovery of Grounded Theory: Strategies for Qualitative Research. Chicago, Aldine, 1967.

36. Strauss A, Corbin J: Basics of Qualitative Research: Grounded Theory Procedures and Techniques. Newbury Park, CA, Sage, 1990.

37. McKnight JL: Health and empowerment. Can J Public Health 76:37-38, 1985.

38. Goodman RM, Speers MA, McLeroy K, Kegler M, Parker E, Smith S, Wallerstein N: An initial attempt at identifying and defining the dimensions of community capacity to provide a basis for measurement. Health Education \& Behavior, in press.

39. Schneider C, Freudenberg N: Local Response to HIV and Substance Abuse: An Ethnographic Study of Four Puerto Rican Low Income Neighborhoods in New York City, 1993-1994. Unpublished manuscript. 
40. 1990 Census Subcommunity Profiles for the City of Detroit, October 1993, United Community Services of Metropolitan Detroit.

41. Babson S: Working Detroit: The Making of a Union Town. Detroit, MI, Wayne State University Press, 1986.

42. Chafets Z: Devil's Night and Other True Tales of Detroit. New York, Vintage, 1990.

43. Herron J: After Culture, Detroit and the Humiliation of History. Detroit, MI, Wayne State University Press, 1993.

44. Chaskin RJ: Defining Neighborhood: History, Theory and Practice. Chicago, Chapin Hall Center for Children at the University of Chicago, 1995.

45. Silverman CJ: Neighboring and urbanism: Commonality versus friendship. Urban Affairs $Q$ 22:312-328, 1986.

46. Village Health Worker Partnership, Fieldnotes, 1996.

47. Conot R: American Odyssey. New York, Morrow, 1974.

48. Neithercut ME: Status of Detroit Area Youth. Detroit, MI, Wayne State University Center for Urban Studies, Detroit Health Department and Skillman Center for Children, November 1993.

49. Sugrue TJ: The structures of urban poverty: The reorganization of space and work in three periods of American history, in Katz MB (ed.): The Underclass Debate: Views From History. Princeton, NJ, Princeton University Press, 1993.

50. Wilson WJ: The Truly Disadvantaged: The Inner City, the Underclass, and Public Policy. Chicago, University of Chicago Press, 1987.

51. Berger MC, Blomquist CG: Income, opportunities and the quality of life of urban residents, in McGeary MG, Lynn LE Jr (eds.): Urban Change and Poverty. Washington, D.C., National Academy Press, 1988.

52. Fainstein SS, Fainstein NI, Hill RC, Judd DR, Smith MP: Restructuring the City, the Political Economy of Urban Redevelopment. New York, Longman, 1981.

53. Lingafelter T, Lingafelter R, Hinton AW, Rausa A: Community Health Workers in Rural Mississippi-Mobilizing Natural Helping Networks. Paper presented at the American Public Health Association Conference, New York, October 1990.

54. Parker EA: Conceptualizing Community Problem-Solving Capacity in Seven African American Southern Communities: Results of a Grounded Theory Study. Ph.D. dissertation, University of North Carolina School of Public Health, 1995.

55. Warren RB, Warren DI: The Neighborhood Organizer's Handbook. Notre Dame, University of Notre Dame Press, 1977.

56. Wellman B, Leighton B: Networks, neighborhoods and communities: Approaches to the study of the community question. Urban Affairs $Q$ 14:363-390, 1979.

57. Thomas RP, Israel BA, Steuart GW: Cooperative problem-solving: The neighborhood self-help project, in Cleary HP, Kichen JM, Ensor PG (eds.): Advancing Health Through Education. Mountain View, CA, Mayfield, 1985.

58. Eng E, Blanchard L: Action-oriented community diagnosis: A health education tool. Int $Q$ Comm Health Educ 11:93-110, 1990-1991.

59. Bullard R (ed.): Unequal Protection: Environmental Justice and Communities of Color. San Francisco, Sierra Club, 1994.

60. Bryant B, Mohai P (eds.): Race and the Incidence of Environmental Hazards: A Time for Discourse. Boulder, CO, Westview, 1992.

61. Don't dump on Delray: The Detroit News, January 24, 1993.

62. Geronimus AT, Bound J, Waidmann TA, Hillemeier MM, Burns PB: Excess mortality among blacks and whites in the United States. New Eng J Med 335:1552-1558, 1996.

63. Schulz AJ, Parker E, Israel BA, Becker A, Maciak BA, Hollis R: Conducting a participatory community-based survey: Gathering and interpreting data for a community intervention on Detroit's East Side. J Public Health Management and Practice, forthcoming.

64. Kretzmann J, McKnight J: Building Communities From the Inside Out. Evanston, IL, Northwestern University Center for Urban Affairs and Policy Research, 1993. 
65. Wang C, Burris MA: Empowerment through photo novella: Portraits of participation. Health Educ Q 21:171-186, 1994.

66. Eng E, Hatch J, Callan A: Institutionalizing social support through the church and into the community. Health Educ Q 12:81-92, 1985.

67. Berger P, Neuhaus R: To Empower People: The Role of Mediating Structures in Public Policy. Washington, D.C., American Enterprise Institute for Public Policy Research, 1977.

68. Israel BA, Schurman SJ, Hugentobler MK: Conducting action research: Relationships between organization members and researchers. J Appl Behav Sci 28:74-101, 1993.

69. Israel BA, Cummings M, Dignan MB, Heaney CA, Perales DP, Simons-Morton BG, Zimmerman MA: Evaluation of health education programs: Current assessment and future directions. Health Educ Q 22:364-389, 1995. 